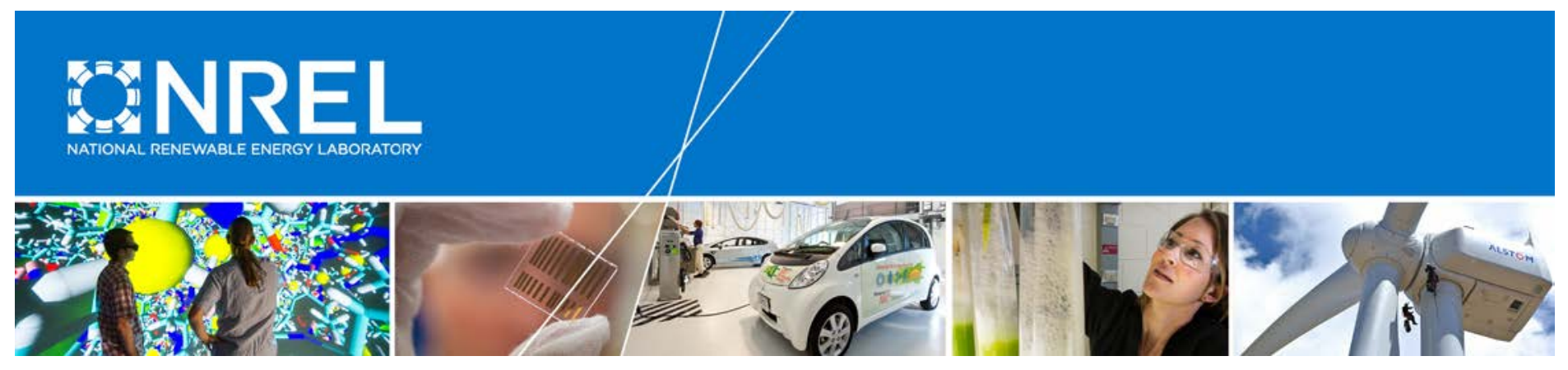

\title{
Energy Auditor and Quality Control Inspector Competency Model
}

Derek Schroeder

U.S. Department of Energy

Kelly Cutchin

Simonson Management Services

Heather Head and Chuck Kurnik National Renewable Energy Laboratory

NREL is a national laboratory of the U.S. Department of Energy Office of Energy Efficiency \& Renewable Energy Operated by the Alliance for Sustainable Energy, LLC

This report is available at no cost from the National Renewable Energy Laboratory (NREL) at www.nrel.gov/publications.

Technical Report

NREL/TP-7A40-71001

May 2018 


\section{Energy Auditor and Quality Control Inspector Competency Model}

Derek Schroeder

U.S. Department of Energy

Kelly Cutchin

Simonson Management Services

Heather Head and Chuck Kurnik National Renewable Energy Laboratory
National Renewable Energy Laboratory 15013 Denver West Parkway Golden, CO 80401

303-275-3000 • www.nrel.gov
NREL is a national laboratory of the U.S. Department of Energy Office of Energy Efficiency \& Renewable Energy Operated by the Alliance for Sustainable Energy, LLC

This report is available at no cost from the National Renewable Energy Laboratory (NREL) at www.nrel.gov/publications.

\section{Technical Report}

NREL/TP-7A40-71001

May 2018

Contract No. DE-AC36-08GO28308 


\section{NOTICE}

This report was prepared as an account of work sponsored by an agency of the United States government. Neither the United States government nor any agency thereof, nor any of their employees, makes any warranty, express or implied, or assumes any legal liability or responsibility for the accuracy, completeness, or usefulness of any information, apparatus, product, or process disclosed, or represents that its use would not infringe privately owned rights. Reference herein to any specific commercial product, process, or service by trade name, trademark, manufacturer, or otherwise does not necessarily constitute or imply its endorsement, recommendation, or favoring by the United States government or any agency thereof. The views and opinions of authors expressed herein do not necessarily state or reflect those of the United States government or any agency thereof.

This report is available at no cost from the National Renewable Energy Laboratory (NREL) at www.nrel.gov/publications.

Available electronically at SciTech Connect http:/www.osti.gov/scitech

Available for a processing fee to U.S. Department of Energy and its contractors, in paper, from:

U.S. Department of Energy

Office of Scientific and Technical Information

P.O. Box 62

Oak Ridge, TN 37831-0062

OSTI http://www.osti.gov

Phone: 865.576.8401

Fax: 865.576.5728

Email: reports@osti.gov

Available for sale to the public, in paper, from:

U.S. Department of Commerce

National Technical Information Service

5301 Shawnee Road

Alexandria, VA 22312

NTIS http://www.ntis.gov

Phone: 800.553 .6847 or 703.605 .6000

Fax: 703.605.6900

Email: orders@ntis.gov 


\section{Acknowledgments}

The work described below was funded by the U.S. Department of Energy's (DOE)

Weatherization Assistance Program (WAP) under the Guidelines for Home Energy Professionals project. The authors want to thank WAP and the home performance industry professionals who participated on the scheme committee and volunteered many hours of their time and expertise to develop the Quality Control Inspector and Energy Auditor competency model. 


\section{Executive Summary}

The National Renewable Energy Laboratory (NREL) is contracted by the U.S. Department of Energy (DOE) Weatherization Assistance Program (WAP) to develop and maintain the resources under the Guidelines for Home Energy Professionals (GHEP) project. The purpose of the GHEP project is to increase the quality of work conducted for residential energy retrofits in the United States through the WAP network and other residential retrofit programs, as described in the Council of Environmental Quality's (CEQ) Recovery through Retrofit October 2009 report. To meet the CEQs goal of "Establishing National Workforce Certifications and Training Standards," NREL was tasked with developing the GHEP resources that include the standard work specifications (SWS) and four advanced, competency-based home energy professionals (HEP) personnel certifications. From 2010-2011, NREL recruited over 40 volunteer subject matter experts (SME) from the WAP network and the home performance industry to serve on committees to develop certification schemes and their requisite job task analysis (JTA) as the foundation of standardized certification and training programs.

As part of the GHEP strategy to increase the quality of work conducted for single-family, residential energy efficiency retrofits, the HEP job task analysis (JTAs) are used as the foundation for quality training programs and trainers. Just as the HEP certifications ensure qualified workers in the field, accredited training programs ensure that individuals receive the proper training to become certified HEP and do the quality work defined in the SWS. DOE contracted with Interstate Renewable Energy Council (IREC) to develop an accreditation for energy efficiency training programs based on the four HEP JTAs. This accreditation is a thirdparty validation an organization is qualified to teach the knowledge, skills, and abilities (KSA) outlined in the JTAs. This accredited training component of the GHEP project guarantees the existence and availability of high quality standardized training programs within the home energy upgrade industry. As of December 2017, 22 Weatherization Training Centers (WTC) held active IREC accreditations specific to the HEP certifications.

To improve the quality of residential retrofits and increase energy savings in the residential market through quality control inspector (QCI) training and certification, from 2013-2017 DOE collected feedback from the WAP network and home performance industry on the successes and barriers to implementing the QCI certification program. The most frequently cited barriers were regarding the QCI JTA, the major component of the certification scheme. The barriers described were the QCI JTA included competencies that ranged from foundational to advanced, included interpersonal skills, or "soft skills" without specifying referenceable material, and the JTA did not demonstrate how the QCI certification required higher competency levels than the other HEP certifications. In practice, the QCI must inspect the work of the EA and the final installed measures of the RIT, yet this level of competency required of each job category was not clearly delineated from one job category to the next. Another major barrier to implement the certifications was management and administration time required of the major stakeholders and training and testing centers to maintain four full-scope certifications. The large range of competencies, the soft skills, and undefined competency levels made it difficult for WTCs to develop curriculum and the exam developers to develop questions that assessed the soft skills adequately. 


\section{The Home Performance Industry QCI and EA Competency Model}

To identify the soft skills, foundational competencies and define the levels of KSAs required to successfully perform the tasks defined in the QCI and EA JTAs, DOE used the Department of Labor's (DOL) Competency Model Clearinghouse resources to develop a QCI and EA

Competency Model. The QCI and EA competency model is different from other models on the DOL's competency model clearinghouse since it was developed using the revised JTAs for the QCI and EA job categories. To keep the QCI and EA competency model consistent with other construction and energy management competency models, DOE and NREL used the existing "Residential Construction Competency Model” and the “Advanced Commercial Building Competency Model” where appropriate.

Once the new QCI and JTAs were completed, the QCI and EA committees reviewed and revised the skeleton QCI and EA Competency Model for the Home Performance Industry that DOE and NREL developed using the resources stated above. After several revision cycles of changes from the committees, the following QCI and EA Competency model was finalized and approved on December 18, 2018 as reflecting the Home Performance Industry’s QCI and EA job category’s competencies.

\section{Competency Model Basics}

\section{Definition of a Competency}

"A competency is the capability to apply or use a set of related knowledge, skills, and abilities required to successfully perform "critical work functions" or tasks in a defined work setting.Not to be confused with competence, a competency describes a behavior, but does not attempt to describe a level of performance.

Competencies often serve as the basis for skill standards that specify the level of knowledge, skills, and abilities required for success in the workplace, as well as potential measurement criteria for assessing competency attainment." i

\section{Definition of a Competency Model}

"A competency model is a collection of competencies that together define successful performance in a particular work setting. Competency models are the foundation for important human resource functions-e.g., recruitment and hiring, training and development, and performance management---because they specify what is essential to select for or to train and develop. Competency models can be developed for specific jobs, job groups, organizations, occupations, or industries.

Industry competency models depict the common knowledge, skills, and abilities in an industry or industry sector. The resulting model forms the foundation on which career paths can be developed. The articulation of broad industry-wide knowledge and skill needs supports the development of a workforce that can perform successfully in a variety of cross-functional teams and make the transition from one job to another."ii

The building blocks model was used to develop the QCI and EA Competency model. The following figure explains the three different tiers of Foundational, Industry and Occupation related competencies. Soft Skills fall into the Foundational Competencies building block. 
Foundational competencies are essential to a large number of occupations and industries. Employers have identified a link between foundational competencies and job performance and have also discovered that foundational competencies are a prerequisite for workers to learn industry-specific skills. Industry-wide technical competencies cut across industry sub-sectors making it possible to create career lattices where a worker can move easily across industry subsectors. Occupational competency models are frequently developed to define performance in a workplace, to design competency-based curriculum, or to articulate the requirements for an occupational credential such as a license or certification.

\section{"Building Blocks" for Competency Models}

This reference source consists of a set of "building blocks" for competency model development. These "building blocks" are arranged in nine tiers including:

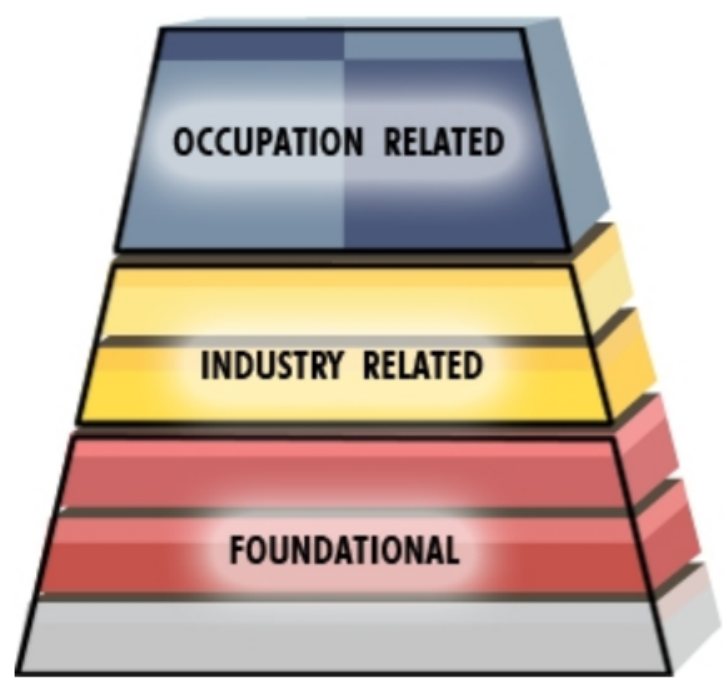

Click on the image to view models

\section{Occupation Related}

- Tier 9 -- Management Competencies

- Tier 8 -- Occupation-Specific

Requirements

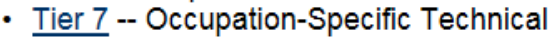
Competencies

- Tier 6 -- Occupation-Specific Knowledge Competencies

Industry Related

- Tier 5 -- Industry-Specific Technical Competencies

- Tier 4 -- Industry-Wide Technical Competencies

Foundational Competencies

- Tier 3 -- Workplace Competencies

- Tier 2 -- Academic Competencies

- Tier 1 -- Personal Effectiveness

The following graphic illustrates the Home Performance Industry's QCI and EA Competency Model described in the content below. 


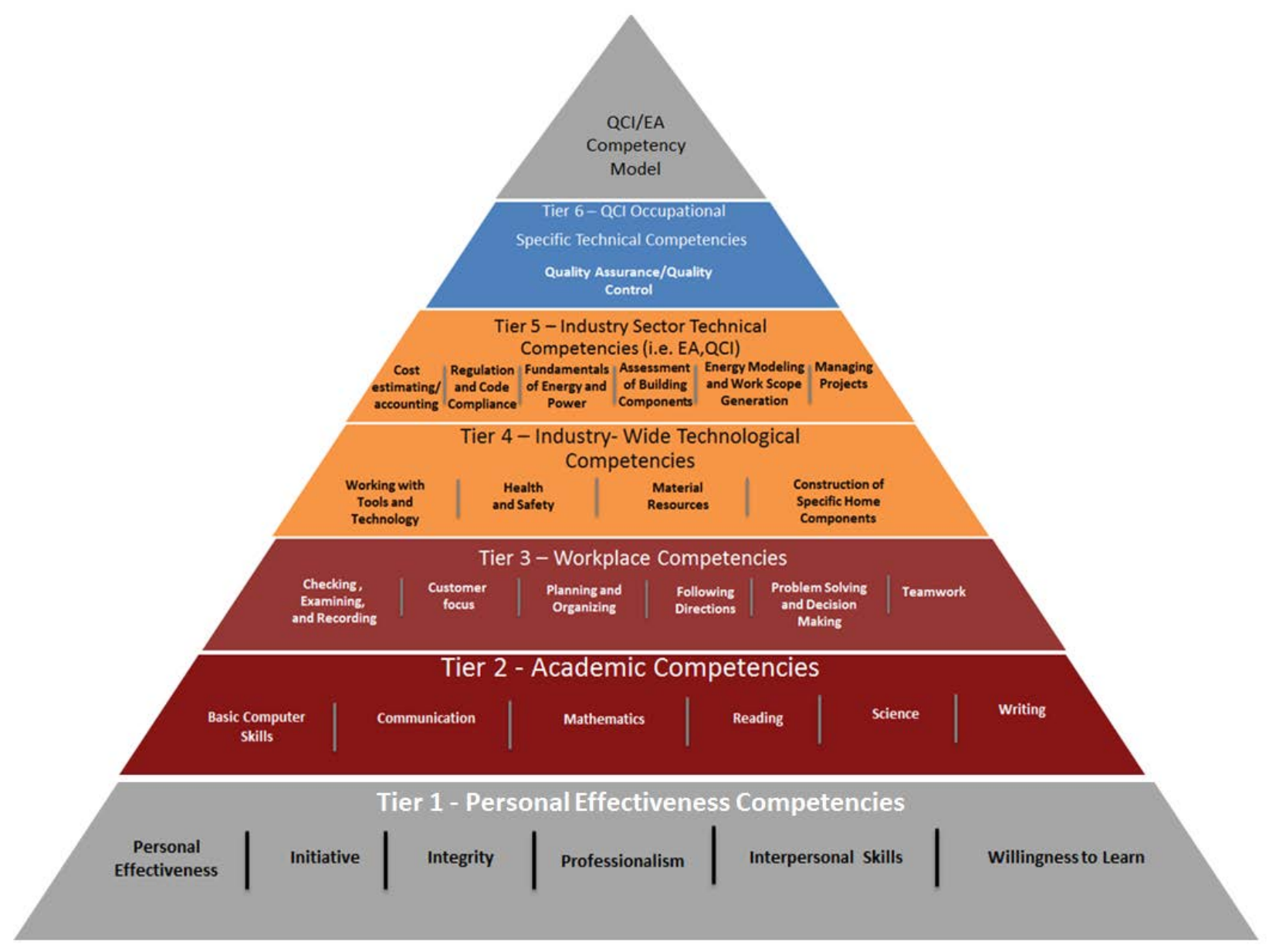

This report is available at no cost from the National Renewable Energy Laboratory (NREL) at www.nrel.gov/publications. 


\section{Table of Contents}

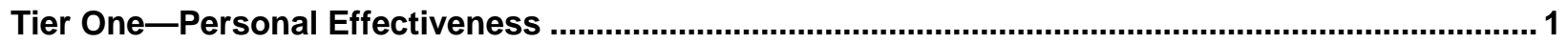

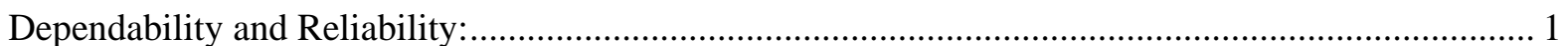

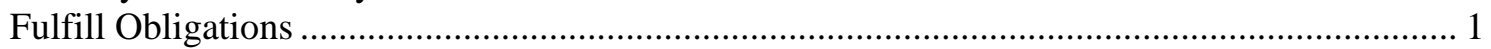

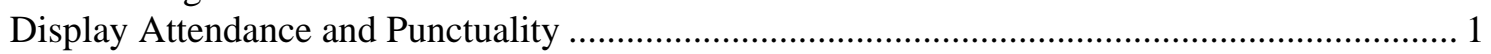

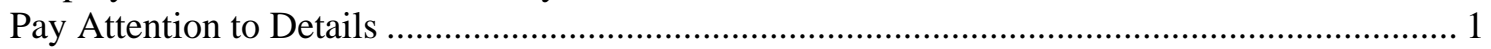

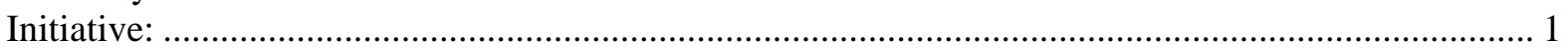

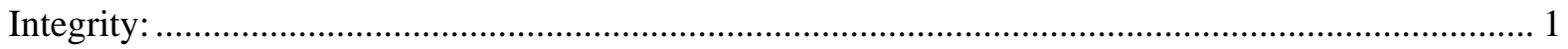

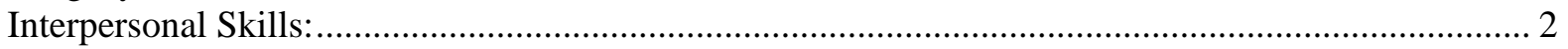

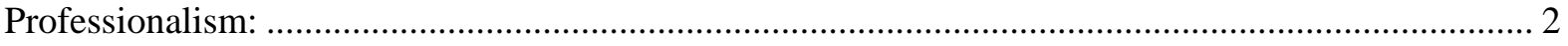

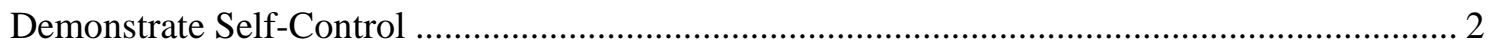

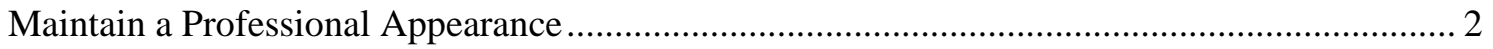

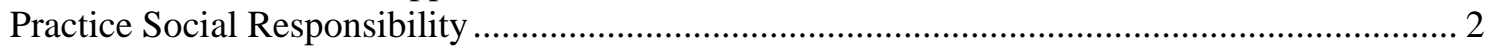

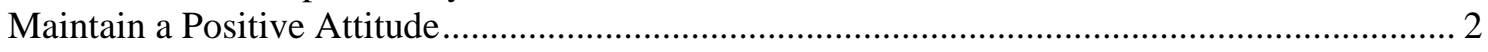

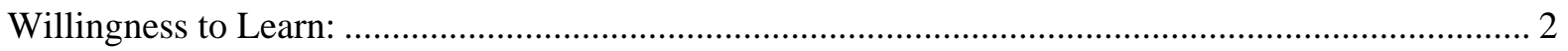

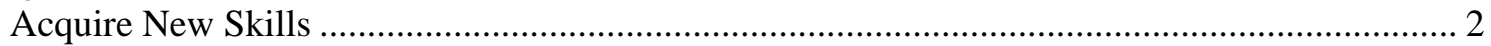

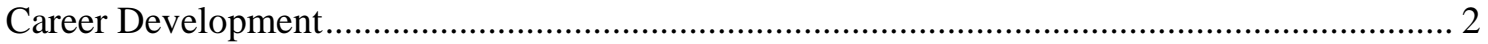

Tier Two-Academic Competencies ……............................................................................... 3

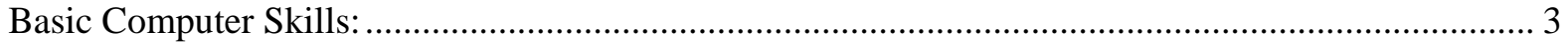

Demonstrate Basic Computing Skills.................................................................................... 3

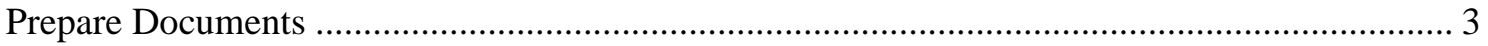

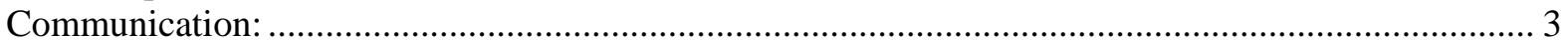

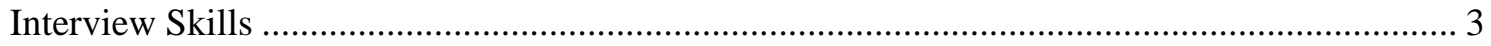

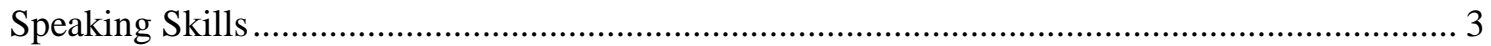

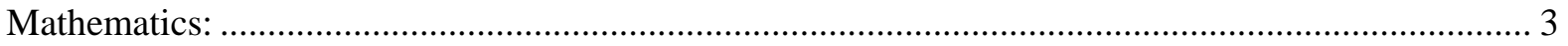

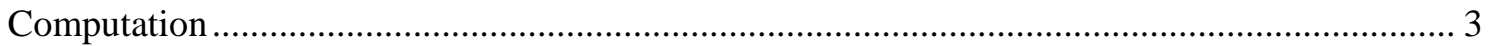

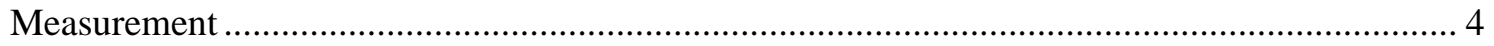

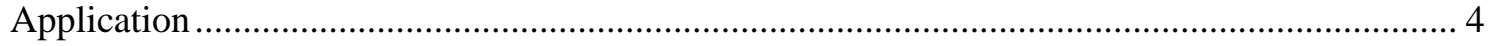

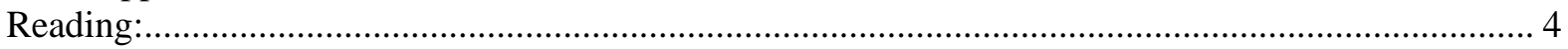

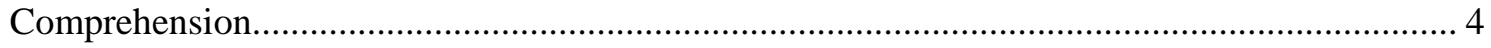

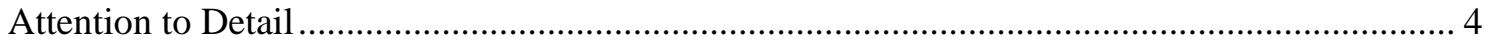

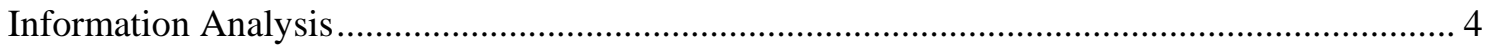

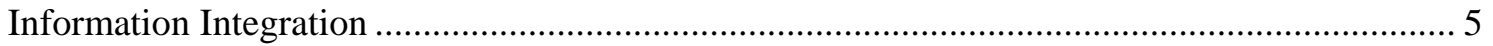

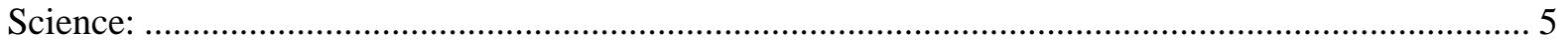

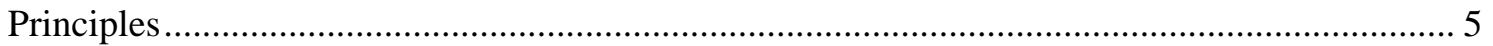

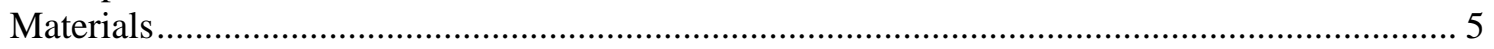

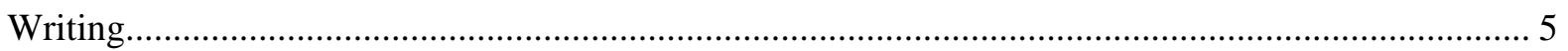

Organize and Develop Effective Written Materials .............................................................. 5

Apply Proper Grammar And Spelling ................................................................................... 5

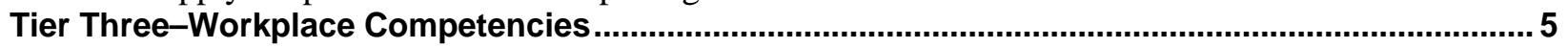

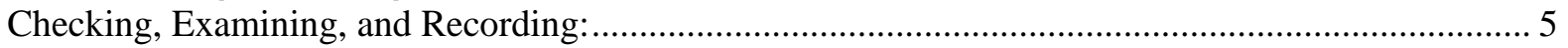

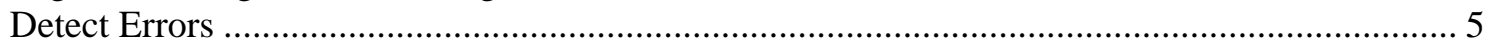

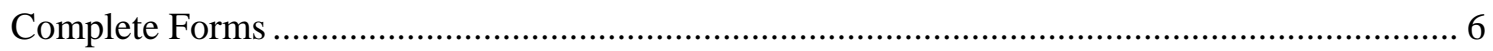

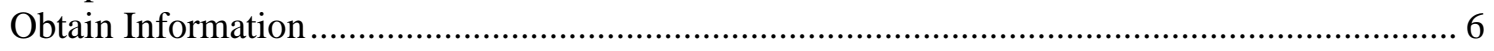

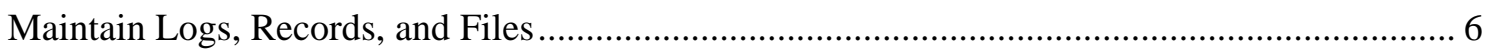

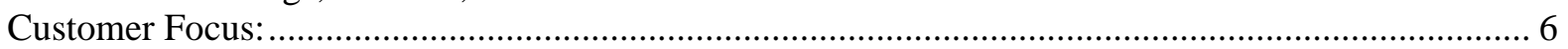

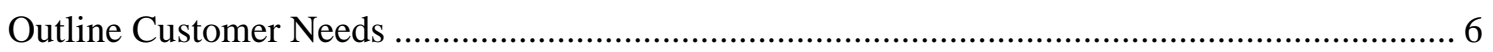

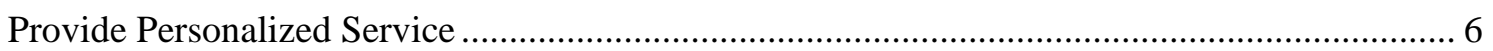

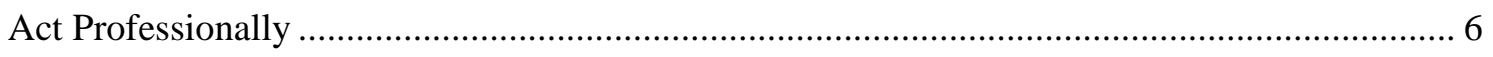

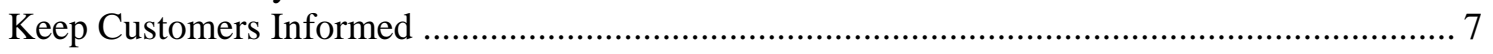




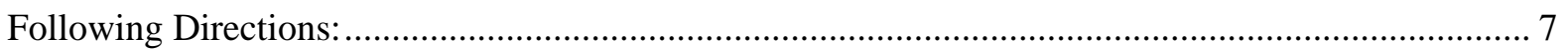

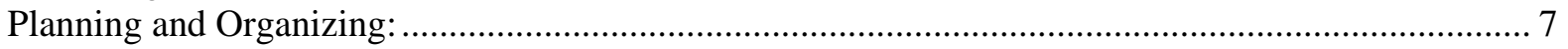

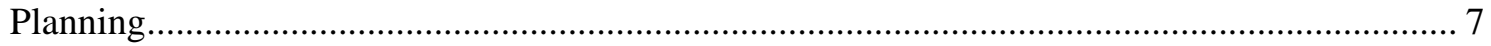

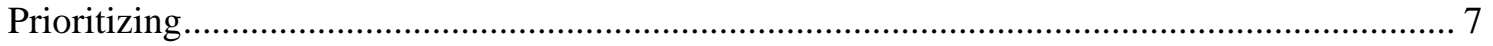

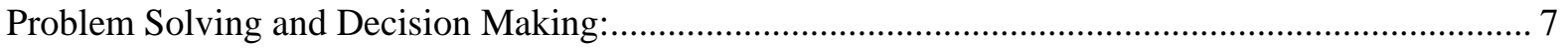

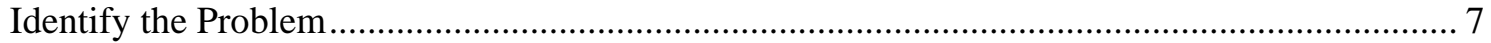

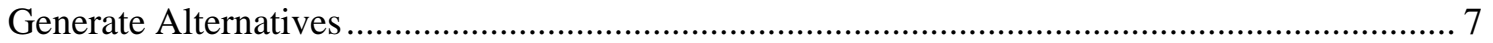

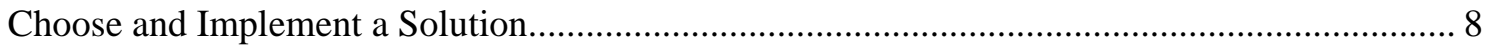

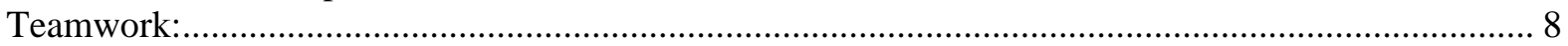

Tier Four-Industry-Wide Technical Competencies-Residential Home Performance ........................ 8

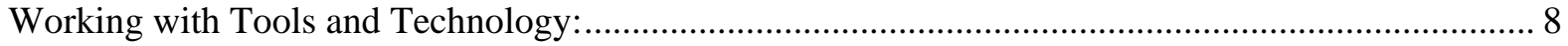

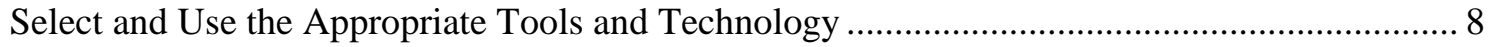

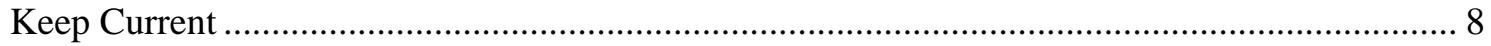

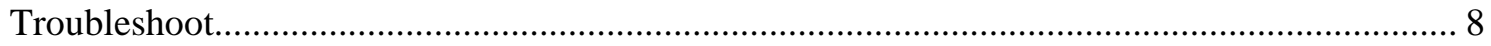

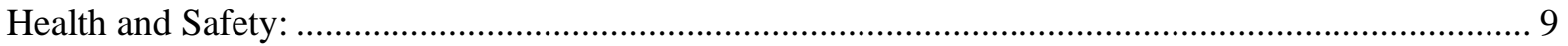

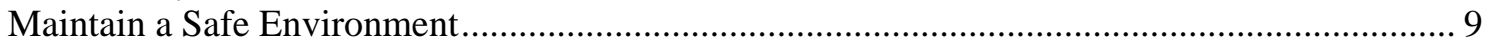

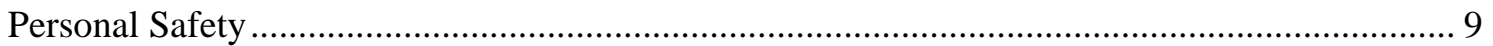

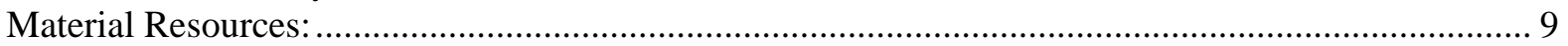

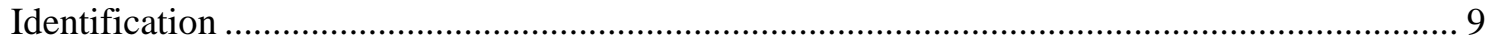

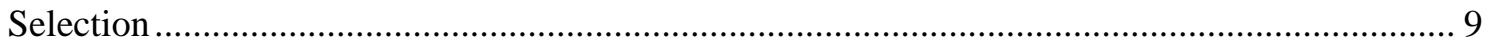

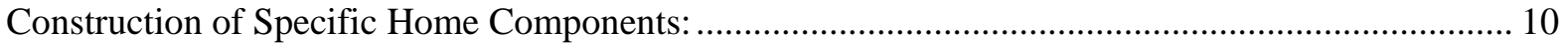

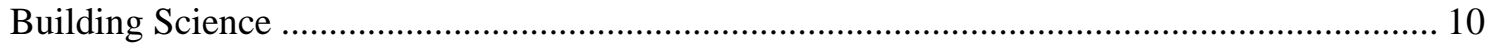

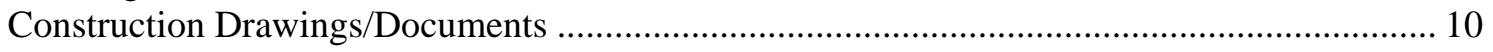

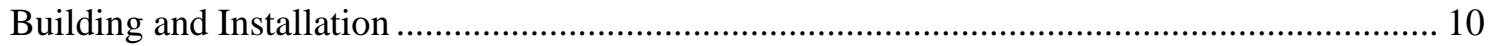

Tier Five-Industry Sector Technical Competencies-Evaluation and Inspection (i.e., Energy

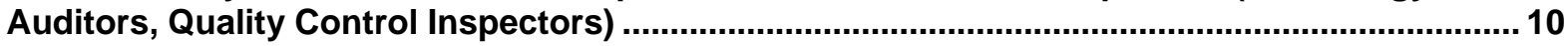

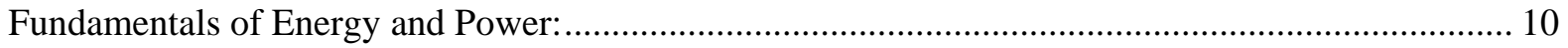

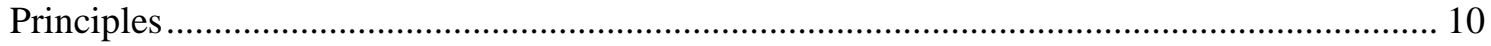

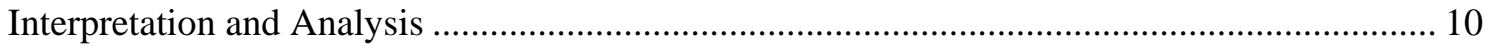

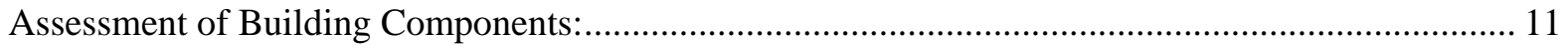

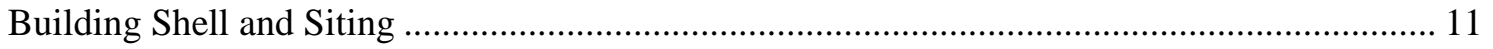

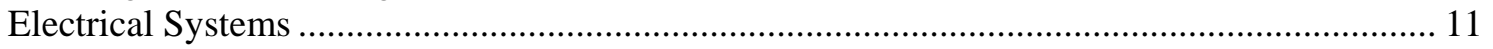

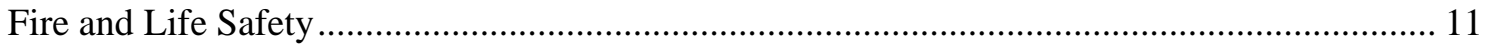

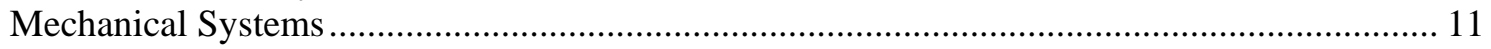

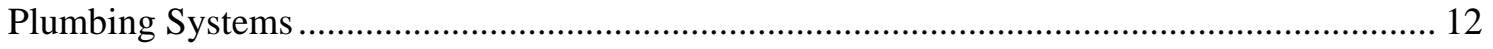

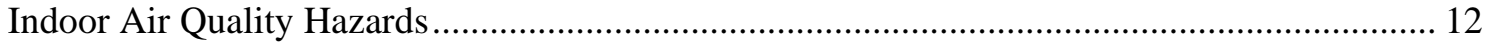

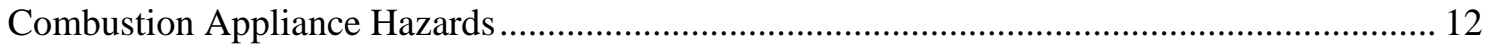

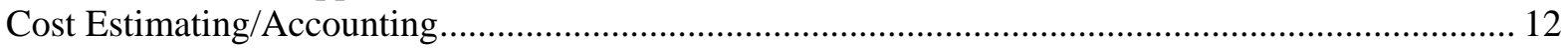

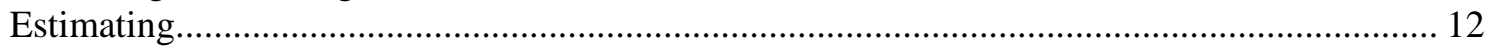

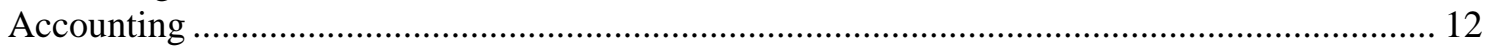

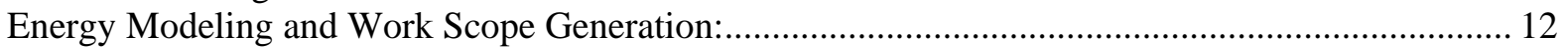

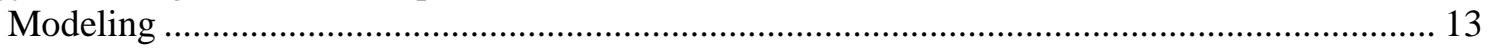

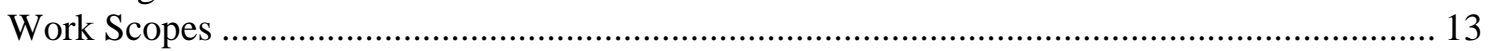

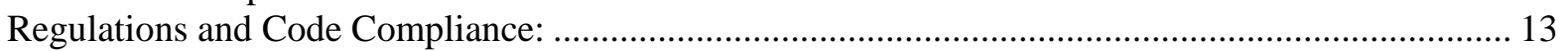

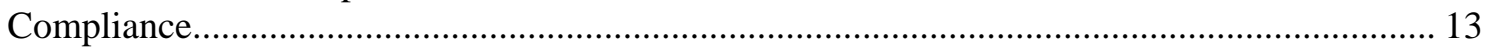

Tier Six-Occupation Specific Technical Competencies-Quality Control Inspector ........................ 13

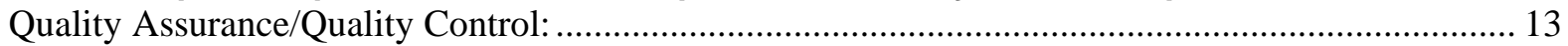

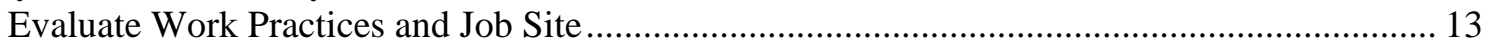

Evaluate Installed Home Retrofit Measures............................................................................ 14

Evaluate Completeness and Compliance of Work Scope and Documentation .......................... 14 


\section{Tier One-Personal Effectiveness}

\section{Dependability and Reliability:}

Display responsible behaviors at work.

\section{Fulfill Obligations}

- Behave consistently and predictably

- Be reliable, responsible, and dependable in fulfilling obligations

- Follow through on commitments and consistently complete assignments by deadlines

- Comply with rules, policies, and procedures such as those of the program, safety, personal hygiene, substance abuse, employee theft, and sexual harassment

- Complete assignments and meet deadlines

\section{Display Attendance and Punctuality}

- Arrive to work fit and on time

- Arrive on time for meetings or appointments

- Respond to phone calls and web conferences on time

\section{Pay Attention to Details}

- Diligently check work to ensure that all essential details have been considered

- Notice errors or inconsistencies and take prompt, thorough action to correct them

- Work accurately and effectively under pressure

\section{Initiative:}

Demonstrate a willingness to work.

- Pursue work with energy, drive, and desire to accomplish tasks

- Persist at a task or problem despite interruptions, obstacles, or setbacks

- Work independently and as a team member to perform effectively even with little or no supervision

- Demonstrate the ability to transition from one task to another

- Take initiative to seek out new responsibilities

- Establish challenging, but realistic work goals

\section{Integrity:}

Display accepted social and work behaviors.

- Apply ethical standards of the industry to workplace/jobsite conduct

- Treat others with honesty, fairness, and respect

- Demonstrate respect for property of customers, employer, and coworkers

- Take responsibility for accomplishing work goals within accepted timeframes

- Accept responsibility for one's decisions and actions 


\section{Interpersonal Skills:}

Display skills to work with others from a range of backgrounds.

- Respect the opinions, customs, and individual differences of others

- Interact respectfully with coworkers or difference cultures, genders, and backgrounds

- Work cooperatively with others on the job and display a positive attitude

- Resolve conflicts and differences to maintain professional relationships

\section{Professionalism:}

Maintain a professional demeanor; take pride in one's work and the work of the organization.

\section{Demonstrate Self-Control}

- Maintain composure and keep emotions in check

- Deal calmly and effectively with stressful or difficult situations

- Accept criticism tactfully and attempt to learn from it

\section{Maintain a Professional Appearance}

- Dress appropriately for occupational and worksite requirements

- Maintain appropriate personal hygiene

\section{Practice Social Responsibility}

- Refrain from lifestyle choices which negatively impact the workplace and individual performance

- Remain free from substance abuse

\section{Maintain a Positive Attitude}

- Project a professional image of oneself and the organization

- Demonstrate a positive attitude towards work

- Take pride in one's work and the work of the organization

\section{Willingness to Learn:}

Understand the importance of learning new information for both current and future problem solving and decision-making.

\section{Acquire New Skills}

- Learn new skills related to the job

- Participate in training opportunities

- Treat unexpected circumstances as opportunities to learn

- Seek out feedback from others to improve job performance

- Accept help from supervisors and co-workers

\section{Career Development}

- Take charge of personal career development by identifying occupational interests, strengths, and opportunities 
- Maintain required CEUs and other program requirements

- Identify opportunities for career advancement and certification requirements

\section{Tier Two-Academic Competencies}

\section{Basic Computer Skills:}

Use information technology and related applications, and software, to convey and retrieve information.

\section{Demonstrate Basic Computing Skills}

- Use basic computer hardware (e.g. PCs, printers) and software (e.g. word processing software, spreadsheet software) to perform tasks

- Describe capabilities of computers and common computer terminology (e.g., program, operating system)

- Organize, store, and retrieve files

\section{Prepare Documents}

- Use word processing programs to create documents and business communications

- Use electronic mail and internet applications

- Use spreadsheet and database applications

- Enter data and type materials quickly and accurately

- Double check work to identify and correct errors

\section{Communication:}

Communicate effectively through active listening, presenting, and fostering support; listen, speak, and signal so others can comprehend.

\section{Interview Skills}

- Interview effectively to gather needed information

- Determine questions to ask to acquire needed information

- Listen effectively

- Practice observational skills, including correctly interpreting body-language if interviewee is uncomfortable

\section{Speaking Skills}

- Speak effectively to be understood by others

- Communicate effectively to varied audiences

\section{Mathematics:}

Use mathematics such as arithmetic, algebra, and geometry to solve problems.

\section{Computation}

- Add, subtract, multiply, and divide with whole numbers, fractions, decimals, and percentages 
- Calculate averages, ratios, proportions, and rates

- Convert decimals to fractions; convert fractions to percentages

\section{Measurement}

- Take measurements of structures, distances, length, width, height, perimeter, area, weight and temperature

- Use and report measurements correctly

- Convert common units of measurement (e.g., from English to metric)

- Find level, plumb, and square

- Read gauges and measurement instruments accurately

\section{Application}

- Choose the right mathematical method or formula to solve a problem

- Perform math operations accurately to complete jobsite/workplace tasks

- Use appropriate formulas for calculating the amount of materials needed to complete a task

- Calculate dimensions from blueprints

\section{Reading:}

Comprehend written sentences, paragraphs, and figures in work-related documents on paper, on computers, or adaptive devices.

\section{Comprehension}

- Locate and interpret written information such as manuals, reports, memos, letters, forms, graphs, charts, tables, calendars, schedules, signs, notices, applications, contracts, regulations, and directions

- Interpret the purpose of written materials

- Comprehend the intended meaning and identify the main ideas expressed in the written material

\section{Attention to Detail}

- Note details and facts

- Detect inconsistencies

- Identify implied meaning and details

- Recognize missing information

\section{Information Analysis}

- Critically evaluate and analyze information in written materials

- Review written information for completeness and relevance

- Distinguish fact from opinion

- Identify trends

- Synthesize information from multiple written materials 


\section{Information Integration}

- Integrate what is learned from written materials with prior knowledge

- Apply what is learned from written material to follow instructions and complete tasks

- Apply what is learned from written material to new situations

\section{Science:}

Use scientific rules and methods to solve problems.

\section{Principles}

- Describe physical principles such as forces, friction, and energy

- Distinguish weight and mass and how it relates to structure supports

- Describe and evaluate the characteristics and hazards of electricity

- Apply basic scientific principles and technology to solve problems and complete tasks

\section{Materials}

- Recognize and describe the interaction of compatible and incompatible substances

\section{Writing}

Use standard English to compile information and prepare written documents.

\section{Organize and Develop Effective Written Materials}

- Communicate ideas, information, and messages which may contain technical material, in a logical and clear manner

- Prepare documents such as written estimates, work orders, memos, and technical reports

- Fill out forms, reports, records, logs, and documents to comply with project requirements

\section{Apply Proper Grammar And Spelling}

- Use standard syntax and sentence structure

- Use correct spelling, punctuation, and capitalization

- Use appropriate grammar (e.g., correct tense, subject-verb agreement, no missing words)

- Use industry jargon, acronyms, and terminology appropriately

\section{Tier Three-Workplace Competencies}

\section{Checking, Examining, and Recording:}

Enter, transcribe, record, store, or maintain information in written or electronic/digital format, including adaptive devices and software.

\section{Detect Errors}

- Detect and correct errors or inconsistencies, even under time pressure

- Identify vague or ambiguous documentation

- Route errors to appropriate person to correct documentation 


\section{Complete Forms}

- Select and complete appropriate forms quickly and completely

- Forward or process forms in a timely and accurate manner

- Attend to and follow through on items requiring action

\section{Obtain Information}

- Obtain appropriate information, signatures, and approvals promptly

- Verify that all information is present and accurate before forwarding materials

- Compile, categorize and verify information or data

- Apply systematic techniques for observing and gathering data

Maintain Logs, Records, and Files

- Organize records and files to maintain data

- Keep logs, records, and files that are up-to-date and readily accessible (e.g., driver logs, flight records, repair records)

- Update logs, records, and files, noting important changes

- File data and documentation in accordance with organization and program requirements

- Maintain photographic documentation

\section{Customer Focus:}

Listen to customer needs and provide personalized assistance to efficiently and effectively address the needs of clients/customers.

\section{Outline Customer Needs}

- Identify internal and external customers

- Listen to what customers are saying and ask questions to identify customer needs, interests, and goals

- Consider possible future needs of the customer

\section{Provide Personalized Service}

- Provide prompt, efficient, and personalized assistance to meet the requirements, requests, and concerns of customers within program guidelines

- Provide thorough, accurate information to answer customers' questions and inform them of commitment times or performance guarantees

- Address customer comments, questions, concerns, and objections with direct, accurate, and timely responses

- Identify and propose appropriate solutions and/or services

- Refer unresolved customer/client concerns to appropriate entities for further action

- Establish boundaries as appropriate for unreasonable customer demands

\section{Act Professionally}

- Be pleasant, courteous, and professional when dealing with internal or external customers

- Develop constructive and cooperative working relationships with customers

- Remain professional when dealing with hostile customers 
Keep Customers Informed

- Follow up with customers during projects and after project completion

- Keep customers up to date about decisions that affect them

- Seek the comments, criticisms, and involvement of customers

- Adjust services based on customer feedback

\section{Following Directions:}

Receive, interpret and carry out assignments with minimal supervision

- Follow directions as communicated in a variety of ways such as writing, speech, computers, or other formats

- Recognize important information in verbal messages

- Interpret complex instructions

- Ask questions to clarify directions

- Act upon instructions to complete the assignment

- Comply with organizational rules, policies, and procedures

\section{Planning and Organizing:}

Plan and prioritize work to manage time effectively and accomplish assigned tasks.

\section{Planning}

- Approach work in a methodical manner

- Plan and schedule tasks so that work is completed on time

- Keep track of details to ensure work is performed accurately and completely

- Anticipate obstacles to project completion and develop contingency plans to address them

- Develop new ways of planning or organizing to accomplish work more efficiently

\section{Prioritizing}

- Prioritize multiple competing tasks

- Perform tasks correctly, quickly, and efficiently according to their relative urgency and importance

\section{Problem Solving and Decision Making:}

Apply critical-thinking skills to solve problems encountered on the work site.

Identify the Problem

- Recognize the existence of a problem

- Identify the nature of the problem define critical issues

- Locate, obtain, and review information relevant to the problem

\section{Generate Alternatives}

- Generate a variety of approaches to the problem

- Think creatively to develop new ideas for and answers to work related problems 
- Use logic and reasoning to identify the strengths and weaknesses of alternative solutions and approaches to problems

\section{Choose and Implement a Solution}

- Choose the best solution after contemplating approaches to the problem

- Commit to a solution in a timely manner

- Use strategies, tools, resources and equipment to implement the solution

- Observe and evaluate the outcomes of implementing the solution to assess the need for alternative approaches and to identify lessons learned

\section{Teamwork:}

Work cooperatively with others to complete work assignments.

- Distinguish the roles and responsibilities of the individual as part of a team and hierarchy of individuals on the jobsite

- Perform responsibly as a team member and assist other members of the work team

- Effectively communicate with all members of the group or team to achieve team goals

- Effectively resolve conflicts with co-workers to maintain a smooth workflow

- Learn from other team members

- Assist others who have less experience or have heavy workloads

\section{Tier Four-Industry-Wide Technical Competencies- Residential Home Performance}

\section{Working with Tools and Technology:}

Select, use, and maintain tools and technology to facilitate work activity.

\section{Select and Use the Appropriate Tools and Technology}

- Identify the hand and power tools appropriate to the work site and to the trade

- Select tools, technology, machinery, and equipment appropriate for a given job

- Demonstrate appropriate use of tools to complete work functions

- Identify potential hazards related to the use of tools

- Operate hand or power tools and equipment in accordance with established operating procedures and safety standards

\section{Keep Current}

- Demonstrate an interest in learning about new and emerging tools and technologies

- Identify sources of information concerning state-of-the-art tools, equipment, materials, and technologies

\section{Troubleshoot}

- Perform routine maintenance on tools, technology, and equipment

- Determine causes of operating errors and decide what to do about it

- Troubleshoot maintenance problems in accordance with established procedures 


\section{Health and Safety:}

Comply with procedures necessary for a safe and healthy work environment; recognize and mitigate work site safety hazards including hazardous materials, environmental hazards, and accident conditions.

\section{Maintain a Safe Environment}

- Follow established jobsite safety practices

- Comply with federal, local, and company health and safety regulations (e.g., OSHA, EPA)

- Identify unsafe conditions and take prompt corrective action

- Properly handle and dispose of hazardous materials

- Follow organizational procedures and protocols for safe evacuation and emergency response

- Maintain a sanitary and clutter free work environment

- Administer first aid and or CPR or summon assistance as needed

- Use Safety Data Sheets (SDS) information to manage, use, and dispose of hazardous materials

- Stay alert to and take preventative action against hazards and threats

- Follow protocol for reporting safety violations

\section{Personal Safety}

- Select, inspect, and use appropriate personal protective equipment such as respiratory protection and fall protection equipment

- Work to create a hazard and accident-free environment

- Know effects of and how to deal with temperature extremes and weather conditions

- Work safely in confined spaces or at heights

- Follow ladder and scaffold safety procedures

- Use equipment and tools safely

\section{Material Resources:}

Identify, move, store, and supply construction and building materials for all types of construction activities.

\section{Identification}

- Identify materials necessary to complete tasks in the trade

- Describe the structure and properties of various materials

- Evaluate waste of resources/materials

- Evaluate necessity for additional/alternative resources/materials

- Differentiate between compatible and incompatible substances

\section{Selection}

- Evaluate and select building materials and assemblies to meet project specifications (e.g., metals, woods, ceramics, concrete, rubber, polymers, composites, etc.)

- Translate criteria used for material section 


\section{Construction of Specific Home Components:}

Apply knowledge of specific materials and methods for construction of home components including foundation, walls, roofing, etc.

\section{Building Science}

- Describe the terms associated with building science

- Exhibit basic interpretation of flows of heat, air, and moisture through the home and various methods used to control them

- Explain what is meant by "the house as a system" as it relates to the evaluation of prospective home retrofit projects

- Have a working knowledge of the environment's impact on the home and its occupants

- Describe the process of "testing in/testing out" as it relates to building science and home retrofit projects

\section{Construction Drawings/Documents}

- Recognize elements and symbols of drawing and specifications

- Visualize three-dimensional forms from two-dimensional drawings

- Locate worksite features included on a work plan

\section{Building and Installation}

- Recognize building techniques and components and explain the basics of their construction and interactions

- Describe the sequencing of events for retrofitting residential buildings

- Correctly specify how to build or install essential home retrofit components

\section{Tier Five-Industry Sector Technical Competencies- Evaluation and Inspection (i.e., Energy Auditors, Quality Control Inspectors)}

\section{Fundamentals of Energy and Power:}

Display basic knowledge related to energy fuel types (e.g., propane, electricity, oil), energy consumption, and power units and definitions.

\section{Principles}

- Explain basic energy concepts and principles

\section{Interpretation and Analysis}

- Interpret specific utility bills, including rate structures and utility contracts

- Translate various energy sources into same units for comparison

- Analyze utility bills, including identification of base loads versus seasonal loads 


\section{Assessment of Building Components:}

Assess building/unit components regarding energy consumption and health \& safety-related issues, and generate a proposed scope of work based on cost-effectiveness, client priorities, and/or other energy efficiency program requirements.

\section{Building Shell and Siting}

- Identify and record fenestration characteristics

- Identify and record building envelope characteristics

- Identify and record site characteristics (e.g., drainage, slope)

- Identify and record points of access to work areas

- Identify and record signs of moisture damage, pest infestation, and other home hazards

- Identify the age of the original structure

- Determine whether the age of the structure necessitates special considerations, e.g., leadsafe work practices or State Historic Preservation review.

- Identify the age of any additions or improvements

- Conduct diagnostic testing (i.e. blower door testing) to determine air leakage of the building envelope

- Determine recommended levels of additional insulation in structure (i.e., floors, walls, attics/ceilings)

- Determine air sealing targets

\section{Electrical Systems}

- Identify and record electrical system characteristics

- Determine if wiring is "live" or not

- Identify knob and tube wiring

- Identify electrical hazards (e.g., frayed wiring, open junction boxes, overloaded circuits)

- Determine whether wiring upgrades are required before insulation may be added to attics, wall cavities, etc.

- Identify and record lighting characteristics

- Meter usage of electric appliances

- Determine whether appliance replacements are cost-effective

Fire and Life Safety

- Identify and record smoke/CO alarm characteristics

- Determine whether additional smoke/CO alarms are required based on applicable codes or program requirements

- Identify and record fuel supply line characteristics

- Conduct gas leak testing to identify any gas leaks

- Determine whether action and/or repair of fuel lines is required

\section{Mechanical Systems}

- Identify and record HVAC equipment characteristics, including make, model, Steady State Efficiency (SSE), temperature rise, etc.

- Identify and record HVAC distribution characteristics, including duct leakage 
- Determine whether HVAC replacement is cost-effective

- Identify and record existing ventilation equipment characteristics, including air flow and venting system termination location

- Determine whether additional ventilation is needed based on local codes and/or program requirements

\section{Plumbing Systems}

- Identify and record water heating appliance characteristics

- Determine whether water heater replacement is cost-effective

- Identify and record plumbing system characteristics (e.g., condition of pipes, existence and location of leaks)

- Determine whether repairs are needed

\section{Indoor Air Quality Hazards}

- Identify volatile organic compounds, conditions that promote radon infiltration, suspected asbestos-containing materials, mold-like substances, etc.

- Determine whether all exhaust appliances are properly vented to the exterior

- Recommend measures to correct identified indoor air quality hazards

- Specify safe-work practices related to identified hazards

\section{Combustion Appliance Hazards}

- Evaluate all combustion appliance systems for health and safety concerns, including CO levels, depressurization concerns, venting systems, ignition issues, etc., applying relevant action levels

- Recommend work based on applicable codes and standards

\section{Cost Estimating/Accounting}

Practice basic accounting and cost estimating related to construction/retrofit and building operations.

\section{Estimating}

- Estimate sizes, distances, and quantities

- Estimate personnel needed for project completion

- Use dimensions, spaces, and structures calculations to estimate resources, materials, equipment and supplies needed for project completion

\section{Accounting}

- Evaluate bid proposals for accuracy

\section{Energy Modeling and Work Scope Generation:}

Use energy modeling software to generate a recommended scope of work, including costeffectiveness of the proposed work. 


\section{Modeling}

- Accurately input housing characteristics, energy prices, and cost-estimates of work being recommended

\section{Work Scopes}

- Generate a scope of work based on the "house as a system" approach that complies with program guidelines and includes cost-effectiveness of recommended measures, using accurate energy costs

- Include health \& safety-related recommendations based on observed housing characteristics and anticipated home characteristics if work scope is accepted (i.e., anticipate potential depressurization issues and recommend proactive response to avoid)

\section{Regulations and Code Compliance:}

Comply with regulations and building codes, and apply industry standards to ensure quality work.

\section{Compliance}

- Be aware of governmental regulations, local and state building codes, contract provisions, and construction standards

- Use information given in regulations and codes correctly

- Identify appropriate authority having jurisdiction to address specific questions

- Recognize and address housing-related environmental hazards (address means either correct or notify appropriate party)

- Craft work orders that will pass job inspections and comply with regulations at all times

- Recognize and safely guide work around environmental concerns

- Operate, maintain, and interpret data from air sampling equipment

- Properly designate how installers shall remove, package, dispose of, and/or document hazardous materials

\section{Tier Six-Occupation Specific Technical Competencies-Quality Control Inspector}

\section{Quality Assurance/Quality Control:}

Evaluate a project for compliance with program or policy requirements and applicable codes and standards, and report on compliance, missed opportunities and/or areas needing attention.

\section{Evaluate Work Practices and Job Site}

- Evaluate work quality and practices in-process

- Evaluate job site management and scheduling (e.g., sequencing, material and equipment staging

- Inspect structures and systems for structural quality, general safety, and conformance to specifications and codes

- Identify potential missed opportunities

- Compare the work performed to the work plan 
- Determine if required documentation is present on the job site (e.g., work order, permits, Safety Data Sheet [SDS], installation specifications)

- Determine which job site worker credentials are needed

\section{Evaluate Installed Home Retrofit Measures}

- Determine if installed measures meet job specifications, customer requirements, and required codes and standards

- List actions necessary to bring installed measures up to compliance (i.e., punch list)

- Conduct tests and inspections of products or processes to evaluate quality

Evaluate Completeness and Compliance of Work Scope and Documentation

- Evaluate a project/job according to specified standards of quality and performance

- Inspect job sites, equipment, structures, or materials to identify the cause of errors or other problems or defects

- Identify questionable costs

- Prepare completion reports (e.g., checklists, required reports, recommend training)

- Report on issues that affect quality

- Determine whether contractual roles and responsibilities have been fulfilled

- Determine pass/fail of work/project based on applicable standards

' https://www.careeronestop.org/CompetencyModel/Info Documents/TAG.pdf page 4

ii https://www.careeronestop.org/CompetencyModel/Info_Documents/TAG.pdf p. 5 